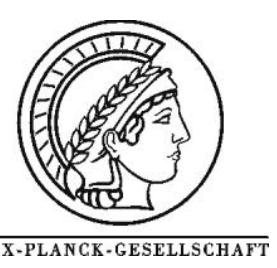

\title{
Oxidative dehydrogenation of propane on silica (SBA-15) supported vanadia catalysts: A kinetic investigation
}

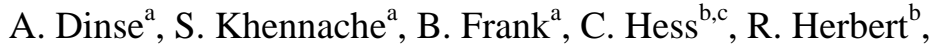 \\ S. Wrabetz ${ }^{\mathrm{b}}$, R. Schlögl ${ }^{\mathrm{b}}$, R. Schomäcker ${ }^{\mathrm{a}^{*}}$ \\ ${ }^{a}$ Department of Chemistry, Technical University of Berlin, Straße des 17. Juni 124, \\ D-10623 Berlin, Germany \\ ${ }^{\mathrm{b}}$ Department of Inorganic Chemistry, Fritz-Haber-Institute of the Max-Planck-Society, \\ Faradayweg 4-6, D-14195 Berlin, Germany \\ ${ }^{\mathrm{c}}$ Eduard-Zintl-Institut für Anorganische und Physikalische Chemie, Technische \\ Universität Darmstadt, Petersenstraße 20, D-64287 Darmstadt, Germany
}

*Corresponding author: e-mail schomaecker@tu-berlin.de., fax: +49 3031421595.

Received 6 August 2008; revised 21 January 2009; accepted 6 March 2009. Available online 20 March 2009

\begin{abstract}
Silica (SBA-15) supported vanadium oxide was used for a kinetic study of the oxidative dehydrogenation of propane in a fixed bed reactor. Prior to this study, spectroscopic characterization using a variety of techniques such as FTIR spectroscopy, Raman spectroscopy, DR UV-Vis spectroscopy and X-ray Phototelectron Spectroscopy revealed the absence of bulk vanadia and a high dispersion of active surface sites for the investigated catalyst. The kinetic data evaluation was based on a formal kinetic approach. Calorimetric measurements were used to determine the heat of adsorption of propane on the catalyst. The data indicate that the primary combustion of propane is negligible. Reaction orders of one for the propane dehydrogenation and propene combustion indicate the participation of these species in the respective rate determining step. The zero reaction order determined for the catalyst reoxidation reveals a participation of lattice oxygen in this reaction step. Higher activation energies of propane dehydrogenation as compared to the propene combustion indicate the participation of the weaker allylic C-H bond of propene in the rate determining step of the propene combustion. This results in higher propene selectivites at elevated temperatures. Kinetic parameters, including apparent and real activation energies and the equilibrium constant of the propane adsorption allowed for a comparison with theoretical predictions and show a good agreement.
\end{abstract}

Keywords: Oxidative dehydrogenation; Propane; Supported vanadia catalysts; SBA-15; Kinetics

\section{Introduction}

Kinetic modelling is a powerful tool to elucidate reaction mechanisms in catalytic reactions. The resulting estimated kinetic parameters can also be used to experimentally verify theoretical DFT calculations. An interesting reaction for kinetic modelling is the oxidative dehydrogenation of propane (ODP) on supported vanadia catalysts [1$3]$. Besides a great effort to describe these catalysts structurally [4-6] many studies tried to elucidate kinetics and mechanism of ODP [7-9]. A great disadvantage of all these studies is the lacking connection between kinetics and analytical characterisation, the so called structure-reactivity relationship. Without such information no substantial improvement of the catalysts for ODP will be possible, providing the basis of an industrial application of this reaction. Furthermore, in many studies mass and heat transfer limitations have not been excluded carefully, making the provided kinetic data unreliable. Also the presence of bulk $\mathrm{V}_{2} \mathrm{O}_{5}$ on the catalyst surface, which leads to unselective side reactions, could not be excluded in many cases. The aim of this study is to fill some of the mentioned gaps. For this sake, a silica (SBA-15) supported vanadia catalyst was chosen to investigate the kinetics of ODP. The chosen catalyst has already been characterized in previous studies [1012]. These studies also take into account the influence of water on the dispersion of surface vanadium sites and de- 
scribe the redoxbehaviour of this catalyst via molecule probing in detail. Some studies found in the literature are based on a Mars-van-Krevelen approach [13-15]. However, in case of a fast reoxidation of the catalyst during the reaction this model can be simplified to a simple power law approach as it was chosen for this study. One key aspect of this work is the use of a silica supported model catalyst for a comparison of parameters like the activation energy and turn over frequencies (TOF) with parameters determined by quantum mechanical calculations [16, 17], which were mainly done for silica supported vanadia clusters. The general reaction network for ODP on which the kinetic modelling in this work is based, is depicted in Fig. 1. A parallel, as well as a consecutive reaction are involved in the overall network. Propene is the desired product, whereas carbon oxides are generated via parallel combustion of propane or by secondary combustion of alkenes. The oxidation of $\mathrm{CO}$ towards $\mathrm{CO}_{2}$ is rather slow and can usually be neglected [18].

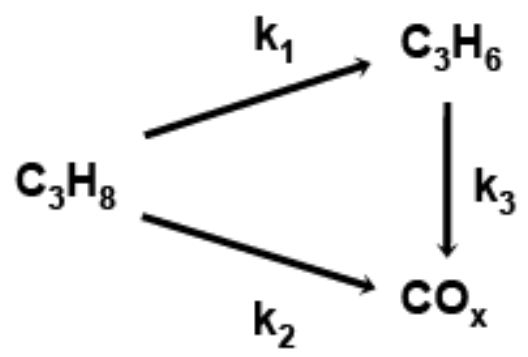

Fig.1: Simplified reaction network of ODP.

\section{Experimental}

\subsection{Catalyst Preparation}

Silica SBA-15 was synthesized according to the literature [19]. Vanadium was incorporated via a multistep grafting ion exchange procedure [11]. In the first step $6.4 \mathrm{ml}$ of 3aminopropyltrimethoxysilane (APTMS, Aldrich) was added to a stirred suspension of $2.5 \mathrm{~g} \mathrm{SBA}-15$ in $100 \mathrm{ml}$ toluene and kept stirring for $12 \mathrm{~h}$ at $65^{\circ} \mathrm{C}$. Afterwards the suspension was filtered and washed with toluene to remove all free amine. In the second step the obtained dry powder was stirred in $150 \mathrm{ml}$ of $0.3 \mathrm{M} \mathrm{HCl}$ for $12 \mathrm{~h}$ at room temperature. Subsequently it was filtered and washed with distilled water and dried at $110^{\circ} \mathrm{C}$ over night. In the third step the functionalized SBA-15 (2 g) was stirred in $60 \mathrm{ml}$ water and $146 \mathrm{mg}$ butylammonium decavanadate $\left(\left[\mathrm{BuNH}_{3}\right]_{6} \mathrm{~V}_{10} \mathrm{O}_{28}\right.$, synthesized according to the literature [20]) was added and stirred for $12 \mathrm{~h}$ at room temperature. The yellow content was filtered, washed and finally calcined for $12 \mathrm{~h}$ at $550^{\circ} \mathrm{C}$ in air. The resulting content of vanadium was $2.7 \mathrm{wt} \%$. The sample is further denoted as V-SBA-15.

\subsection{Calorimetric Measurements}

For calorimetric measurements, a Calvet calorimeter (MS70 SETARAM) has been combined with a housedesigned high vacuum system, which enables the dosage of probe molecules within a range of $0.02 \mu \mathrm{mol}$. The pressurecontrolled dosing systems allows for the detection of adsorbed amounts of molecules (adsorption isotherm) as well as differential heat of adsorption and gives the possibility to elucidate the distribution of the adsorption sites along the range of adsorption heats [21].

The samples were pretreated and activated under mild conditions to minimize thermal and mechanical stress. All samples were pressed under low pressures (125 MPa; V-SBA-15 nearly stable up to $376 \mathrm{MPa}$ [22], decrease of surface area (10\%) of SBA-15 beyond $296 \mathrm{MPa}$ [23]) and cut into small pellets, which were sieved to a diameter of 0.4 to $0.6 \mathrm{~mm}$ due to ultra high vacuum (UHV) conditions. The activation was conducted separately in the calorimetric cell connected to a turbomolecular-pump (Balzers). The activation was performed for $17 \mathrm{~h}$ at $373 \mathrm{~K}$. The final pressure in the degassed cell was $10^{-6} \mathrm{mbar}$. The cell was cooled down to $313 \mathrm{~K}$, placed inside the calorimeter and connected to the micro calorimetric gas-adsorption system, subsequently. Propane 3.5 (Messer Griesheim) was dosed stepwise. Pressures (mbar), adsorption temperatures $\left({ }^{\circ} \mathrm{C}\right)$ and the heat signals $(\mathrm{V})$ were recorded.

\subsection{Catalytic measurements}

Experimental runs were carried out at temperatures between 673 and $773 \mathrm{~K}$ using u-shaped fixed bed quartz reactors at atmospheric pressure. For the measurements, catalyst sample amounts between 200 - $900 \mathrm{mg}$ were portioned to the reactor. Using synthetic air as oxygen source, propane and oxygen were fed in the ratio $1: 1\left(\mathrm{C}_{3} \mathrm{H}_{8} / \mathrm{O}_{2} / \mathrm{N}_{2}\right.$ $=16.9 / 16.9 / 67.5), 2: 1\left(\mathrm{C}_{3} \mathrm{H}_{8} / \mathrm{O}_{2} / \mathrm{N}_{2}=29.1 / 14.5 / 56.4\right)$ and 4:1 $\left(\mathrm{C}_{3} \mathrm{H}_{8} / \mathrm{O}_{2} / \mathrm{N}_{2}=45 / 11.3 / 45\right)$ with a gas hourly space velocity (GHSV) of $6.610^{2}-6.610^{3} \mathrm{~h}^{-1}$. The propane conversion was kept below $10 \%$, which enables isothermal and differential conditions. Mass transfer limitations were avoided by working with particle sizes of 200 to $300 \mu \mathrm{m}$. This is described in more details elsewhere [24]. In addition, to check for diffusional limitations the Weisz modulus $\Psi$ ' considering propane as the limiting reactant was estimated. The Weisz modulus describes the ratio of reaction rate to reactant diffusion rate and is defined by eq. 1

$$
\Psi^{\prime}=L^{2} \cdot \frac{m+1}{2} \cdot \frac{r_{e f f} \cdot \rho_{c a t}}{D_{e f f, C_{3} H_{8}} \cdot c_{C_{3} H_{8}}}
$$

$\mathrm{L}$ : Characteristic length of catalyst particle $=10^{-4} \mathrm{~m}$

$\mathrm{m}$ : Reaction order of propane $\quad=1$

$r_{\text {eff }}$ : Measured reaction rate $\quad=6 \times 10^{-3} \mathrm{~mol} \mathrm{~s}^{-1} \mathrm{~kg}^{-1}$

$\rho$ : Catalyst density $\quad=2 \times 10^{3} \mathrm{~kg} \mathrm{~m}^{-3}$ 


$$
\begin{array}{ll}
\mathrm{D}_{\text {eff }}: \text { Effective diffusivity } & =10^{-5} \mathrm{~m}^{2 \cdot} \cdot \mathrm{s}^{-1} \\
\mathrm{c}: \text { Concentration } & =8 \mathrm{~mol} \mathrm{~m}^{-3}
\end{array}
$$

With an effective rate of $6 \times 10^{-3} \mathrm{~mol} \mathrm{~s}^{-1} \mathrm{~kg}^{-1}$ estimated for $500{ }^{\circ} \mathrm{C}, 10 \%$ propane conversion and the data given above a Weisz modulus of 0.15 is calculated indicating that the reaction proceeds much slower than the propane diffusion and no mass transfer limitation needs to be considered at $500{ }^{\circ} \mathrm{C}$ or lower temperatures.

Concentrations of the individual components were calculated from a GC analysis of the product gas and expressed in $\mathrm{mol} \mathrm{m}^{-3}$.

\subsection{Parameter determination}

Propane conversion $X$ and propene selectivity $S$ as functions of the respective concentration $c_{i}$ were calculated from eqs. (2) and (3)

$$
\begin{aligned}
& X=1-\frac{c_{C 3 H 8}}{c_{C 3 H, 0}} \\
& S=\frac{c_{C 386}}{c_{C 338,0}-c_{C 3 H 8}}
\end{aligned}
$$

Initial reaction rates at low propane conversions were calculated according to eq. 4

$$
r_{0}=c_{0, C_{3} H_{\varepsilon}} \cdot \frac{d X}{d \tau}
$$

with

$\mathrm{r}_{0}$ being the initial reaction rate, $\mathrm{c}_{0}$ the respective initial reactant concentration and $\tau$ the modified residence time calculated from catalyst mass and gas flow rate $\mathrm{m}_{\text {cat }} / \mathrm{F}$. The ODP reaction is a complex reaction network containing essentially the following parallel and consecutive reactions $[25,26]$ :

$$
\begin{aligned}
& C_{3} H_{8(g)}+\stackrel{+V}{V} O_{(s)} \rightarrow C_{3} H_{6(g)}+H_{2} O_{(g)}+\stackrel{+H}{V}(s)
\end{aligned}
$$

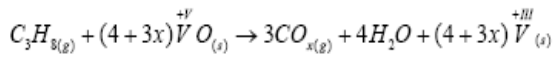

$$
\begin{aligned}
& \mathrm{C}_{3} \mathrm{H}_{6(g)}+(3+3 x) \stackrel{+v}{V} \mathrm{O}_{(s)} \rightarrow 3 \mathrm{CO}_{x(g)}+3 \mathrm{H}_{2} \mathrm{O}+(3+3 x) \stackrel{+H I}{V_{(s)}} \\
& \mathrm{CO}_{(g)}+\stackrel{+V}{V} \mathrm{O}_{(s)} \rightarrow \mathrm{CO}_{2(g)}+\stackrel{+H I}{V}(s) \\
& O_{2(g)}+2 \stackrel{+H I}{V}(s) \rightarrow 2 \stackrel{+V}{V} O_{(s)}
\end{aligned}
$$

Homogeneous contributions to this reaction scheme were observed only at temperatures above $773 \mathrm{~K}$
Simplifications for eqs (A) - (E) are the following: The conversion/selectivity-trajectories presented in Fig. 2 have an extrapolated intercept at nearly $100 \%$ propene selectivity, indicating that primary propane combustion (B) can be neglected in this case (i) and (ii) the ratio of $\mathrm{CO}$ and $\mathrm{CO}_{2}$ was nearly constant at a value of 1.5 , independent from the propane conversion. This indicates a slow $\mathrm{CO}$ oxidation to $\mathrm{CO}_{2}$ and the reaction scheme simplifies to:

$$
\begin{aligned}
& \mathrm{C}_{3} \mathrm{H}_{\mathrm{s}(\mathrm{g})}+\stackrel{+V}{\mathrm{~V}} \mathrm{O}_{(s)} \rightarrow \mathrm{C}_{3} \mathrm{H}_{6(g)}+\mathrm{H}_{2} \mathrm{O}_{(g)}+\stackrel{+H}{\mathrm{~V}}(s) \\
& \mathrm{C}_{3} \mathrm{H}_{6(g)}+7 \stackrel{+V}{\mathrm{~V}} \mathrm{O}_{(s)} \rightarrow 2 \mathrm{CO}+\mathrm{CO}_{2}+3 \mathrm{H}_{2} \mathrm{O}+7 \stackrel{+H}{\mathrm{~V}}(s) \\
& \mathrm{O}_{2(\mathrm{~g})}+2 \stackrel{+H}{\mathrm{~V}}(s) \rightarrow 2 \stackrel{+V}{\mathrm{~V}} \mathrm{O}_{(s)}
\end{aligned}
$$

Elimination of the catalytic species results in the stoichiometric equations for the stable compound, eq. 5 and 6 :

$$
\begin{aligned}
& \mathrm{C}_{3} \mathrm{H}_{8}+0.5 \mathrm{O}_{2} \rightarrow \mathrm{C}_{3} \mathrm{H}_{6}+\mathrm{H}_{2} \mathrm{O} \\
& \mathrm{C}_{3} \mathrm{H}_{6}+3.5 \mathrm{O}_{2} \rightarrow \mathrm{CO}+\mathrm{CO}_{2}+3 \mathrm{H}_{2} \mathrm{O}
\end{aligned}
$$

Please note that eqs. (A) - (E) are based on the following assumption: One catalytic turn over leads to a reduction of vanadium $(+5)$ to vanadium $(+3)$. The assumption was made despite DFT calculations for silica supported vanadium oxide and bare $\mathrm{V}_{2} \mathrm{O}_{5}[16,17]$ predicting a lower activation barrier for reaction pathways only including a vanadium oxidation state of $(+4)$. However, such mechanisms would not change the stoichiometry of eq. 5 and 6. Furthermore, reaction pathways including vanadium (+III) as short lived species could experimentally not be thoroughly excluded so far.

The material balances for the stable reactants and products in the applied tube reactor is given by

$$
\begin{aligned}
& \frac{d c_{C_{G} H_{8}}}{d \tau}=-r_{1} \\
& \frac{d c_{C_{1} H_{6}}}{d \tau}=r_{1}-r_{2} \\
& \frac{d c_{O_{2}}}{d \tau}=0.5 \cdot r_{1}-3.5 \cdot r_{2}
\end{aligned}
$$

Rate expressions for ODH and consecutive propene combustion $r_{1}$ and $r_{2}$, respectively, are:

$$
\begin{aligned}
& r_{1}=k_{1, \text { eff }} \cdot \exp \left(\frac{-E_{M 1 \text { app }}}{R \cdot T}\right) \cdot c_{C_{S} H_{s}}^{n 1} \cdot c_{O_{2}}^{m 1} \\
& r_{2}=k_{2, a f f^{\prime}} \cdot \exp \left(\frac{-E_{A 2, \mu p p}}{R \cdot T}\right) \cdot c_{C H_{H}}^{n 2} \cdot c_{O_{2}}^{m 2}
\end{aligned}
$$


The rate constants $\mathrm{k}_{1, \text { eff }}$ and $\mathrm{k}_{2, \text { eff }}$ are effective rate constants combining the rate constants of the reaction (A) and (C1) with the binding constant of the substrates and the catalyst concentration. The dependence of the rate on the concentration of the hydrocarbon and oxygen is expressed in a power law expression, because the exact interaction of the hydrocarbon with the catalyst as well as the coupling of reaction $\mathrm{E}$ with $\mathrm{A}$ and $\mathrm{C}$ is not yet known. Numerical integration for data evaluation was done by using "Athena Visual Studio" Version 11.0 which uses the least square method for fitting.

For the determination of the equilibrium constants for the propane adsorption on V-SBA-15 a Langmuir equation was fitted a set of experimental data. The Langmuir isotherm is given in eq. (12):

$$
\frac{N}{N_{0}}=\frac{K \cdot p}{1+K \cdot p}
$$

with $\mathrm{N}$ the number of adsorbed molecules, $\mathrm{N}_{0}$ the number of molecules for a monolayer coverage of the sample, $p$ the pressure and $\mathrm{K}$ the equilibrium adsorption constant.

$K=K_{\infty} \cdot \exp \left(\frac{\Delta H}{R \cdot T}\right)$

with $\Delta \mathrm{H}$ the heat of adsorption.

\section{Results}

The grafting - ion exchange procedure used for the incorporation of vanadium into the porous silica matrix results in highly dispersed vanadia species [11]. For the sample used here $\left(0.7 \mathrm{~V} \mathrm{~nm}^{-2}\right)$, no crystalline $\mathrm{V}_{2} \mathrm{O}_{5}$ was observed with visible Raman spectroscopy [10]. By combining Raman spectroscopy, DR UV-Vis spectroscopy as well as X-ray photoelectron spectroscopy (XPS) we recently demonstrated the strong increase in the dispersion of the supported vanadia species upon dehydration [4]. The changes in the dispersion are accompanied by distinct structural changes, i.e., changes in the vanadium coordination as well as the size of the vanadia aggregates. Detailed studies using transmission IR spectroscopy using NO as probe molecule revealed the presence of bridged nitrates implying the presence of dimeric/polymeric vanadia species [12].

Fig. 2 shows the selectivity-conversion trajectories of V-SBA-15 as function of temperature. It can be seen, that the selectivity increases with temperature, indicating a weaker temperature dependence of oxidation of propene in comparison to propene formation by $\mathrm{ODP}$, i.e. $\mathrm{E}_{\mathrm{A} 1, \text { app }}>$ $\mathrm{E}_{\mathrm{A} 2 \text {,app. }}$

Fig. 3 shows an Arrhenius plot for the determination of the apparent activation energy of ODP from the initial rates of propane conversion. The calculated value of $90 \mathrm{~kJ}$ $\mathrm{mol}^{-1}$ can be used as an orientation for the subsequent determination of the kinetic parameters for the complete reaction network.

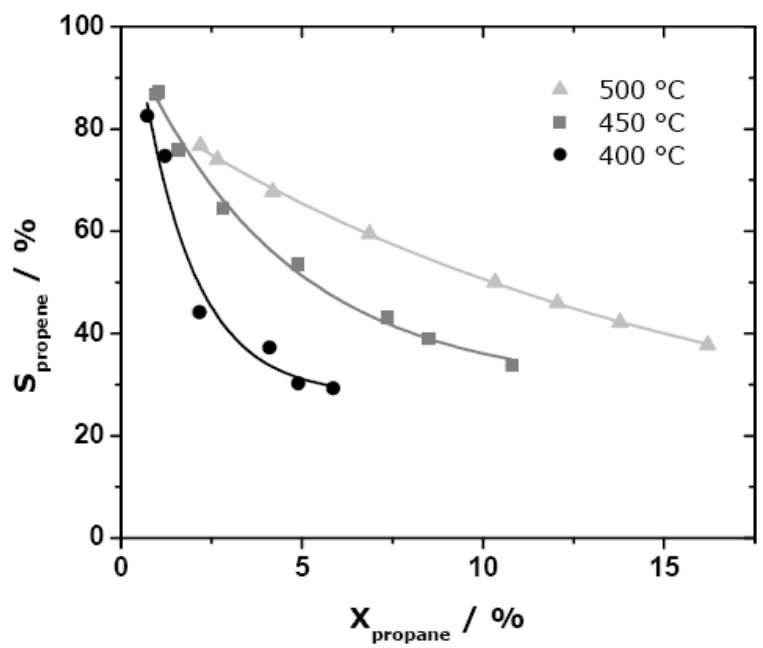

Fig.2: Selectivity-Conversion dependence of ODP at different temperatures for a SBA-15 supported vanadia catalyst.

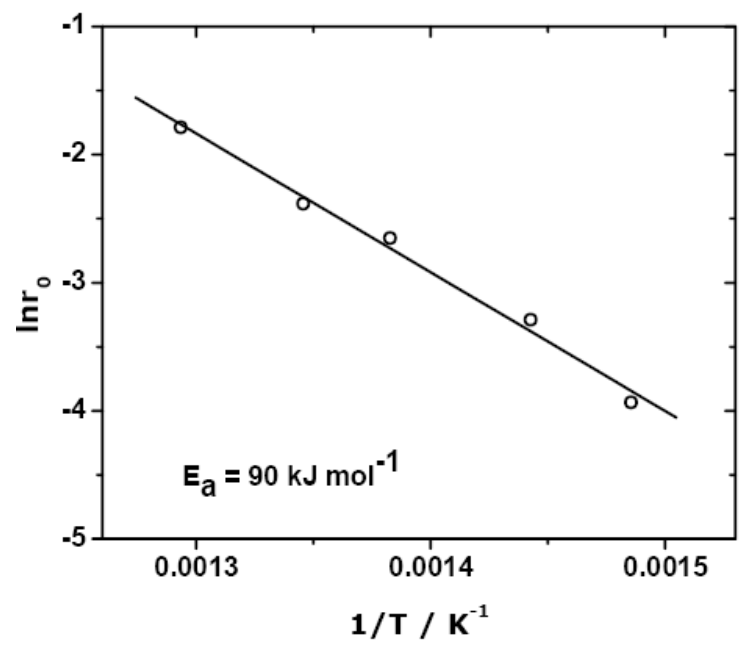

Fig.3: Arrhenius plot for the determination of the activation energy of ODP.

The reaction orders for the oxidative dehydrogenation of propane were determined by a differential method studying the dependence of the initial rates on the individual initial concentration of the reactants. The logarithmic form of eq. 10 yields eq. 12 .

$$
\ln r_{0}=\ln k_{s f f}+n \cdot \ln c_{0, C_{3} H_{8}}+m \cdot \ln c_{0, O_{2}}
$$

with $\mathrm{r}_{0}$ the rate, $\mathrm{k}_{1, \text { eff }}$ the effective rate constant, $\mathrm{c}_{0}$ the respective reactant concentration, $\mathrm{n}$ the reaction order of 
ODP with respect to propane and $m$ the order for oxygen, respectively. The reaction orders for propane and oxygen were determined by plotting the logarithm of the initial rate versus the logarithm of the concentration of the corresponding component. From the resulting slope the reaction orders were found to be 1 and 0 for propane and oxygen, respectively (Fig. 4).

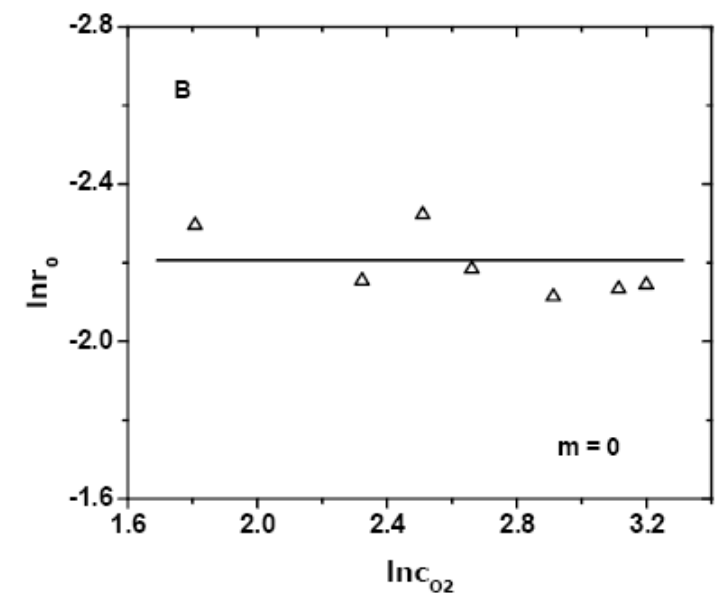

Fig. 4: Determination of the reaction orders for propane (A) and oxygen (B) in the dehydrogenation step.

The reaction orders of the consecutive reaction of propene and oxygen cannot be determined in terms of the particular partial reaction. This is because of propene being a stronger reducing agent than propane, resulting in a lower average oxidation state of the catalyst [24].

In order to get more insight into the consecutive propene combustion reaction and its reaction orders an indirect method was used. This is done by considering the selectivity dependence on the conversion of ODP at different partial pressures of propane and oxygen, respectively. The propene selectivity dependence on the propane conversion indicates certain ratios of the reaction orders with respect to the reactants. If a change in the feed ratio of the substrates at the reactor inlet does not affect the selectivity towards propene, the consecutive reaction must be of an order of one and zero for propene and oxygen, respectively. If this is not the case, selectivity would vary strongly with the partial pressure of the reactant gas. For further allocation a simulation of the propene selectivity with different reaction orders for propane, propene and oxygen is depicted in Fig. 5.

Fig. 6 shows the measured selectivity-conversion trajectories for different initial concentrations of propane and oxygen. It can be seen, that the propene selectivity is not affected by this variation. This leads to the conclusion that the reaction orders of the consecutive propene combustion are 1 and 0 for propene and oxygen, respectively, as shown by comparison with the simulation.
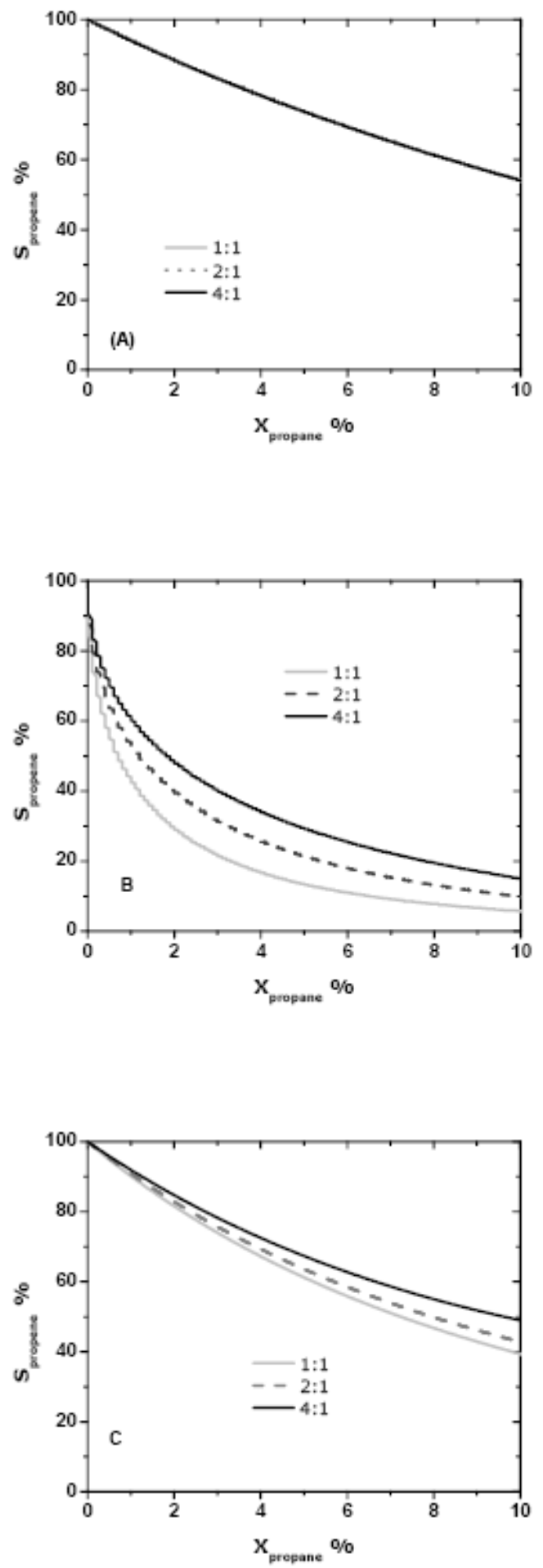

Fig. 5: Simulation of Selectivity-Conversion trajectories for ODP at $450{ }^{\circ} \mathrm{C}$, for different reaction orders of propene and oxygen, respectively, in case of variable inlet concentrations of propane and oxygen. (A) Reaction order of one for propene and zero for oxygen, (B) reaction order of 0.5 for propene and zero for oxygen, (C) reaction order of 1 for propane and 0.5 for oxygen. Simulations were performed for 1 bar overall pressure and the partial pressures of the reactants chosen for the experiments. 


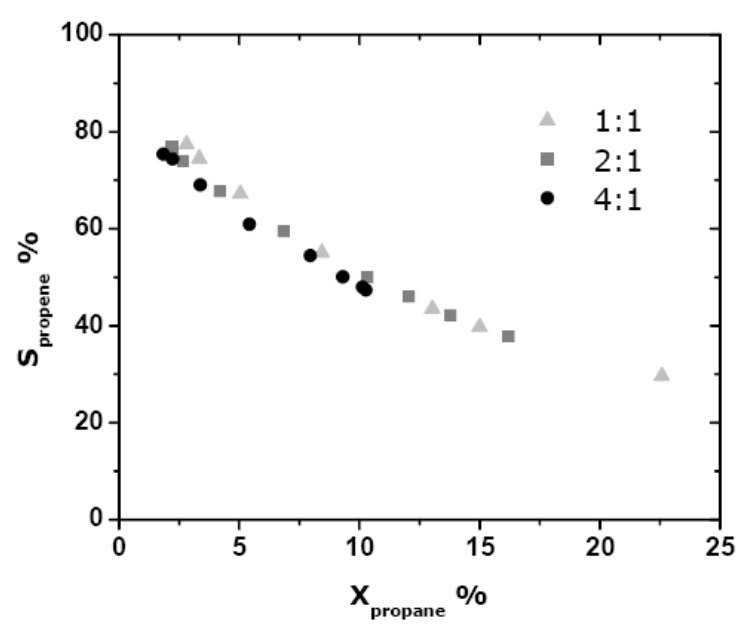

Fig. 6: Experimental selectivity/conversion dependence for different propane/oxygen ratios

The experimentally determined reaction orders, discussed above, were subsequently implemented into the kinetic model for the reaction network, which consisted of a simple consecutive reaction of propane to propene and propene to carbon oxides and water, respectively. The respective equations are given in (10) and (11). The material balances for the stable compounds were fitted to of experimental data at five different temperatures $(673 \mathrm{~K}, 693 \mathrm{~K}, 723 \mathrm{~K}$ and $773 \mathrm{~K})$ and three different ratios of propane to oxygen (4:1, 2:1 and 1:1). Fitting variables were the apparent activation energies for ODP as well as for propene combustion and the respective pre-exponential factors $\mathrm{k}_{1, \text { eff }}$ and $\mathrm{k}_{2, \text { eff. }}$.

The pre-exponential factors, reaction orders and apparent activation energies, determined by fitting the concentration profiles to the experimental data are depicted in table 1 .

Table 1: Kinetic parameters for ODP reaction network.

\begin{tabular}{lllll}
\hline & $\mathrm{k}_{0, \mathrm{eff}, 0}$ & $\mathrm{E}_{\mathrm{A}, \mathrm{app}, \mathrm{x}}$ & & \\
$\mathrm{x}$ & $\mathrm{ml} \mathrm{mg}^{-1} \mathrm{~min}^{-1}$ & $\mathrm{~kJ} \mathrm{~mol}^{-1}$ & $\mathrm{n}_{\mathrm{x}}$ & $\mathrm{m}_{\mathrm{x}}$ \\
\hline 1 & $2260 \pm 1270$ & $103 \pm 6$ & 1 & 0 \\
2 & $0.7 \pm 0.5$ & $34 \pm 18$ & 1 & 0 \\
\hline
\end{tabular}

Parity plots, shown in Fig. 7 indicate a good agreement of experimentally determined data and concentrations predicted by the derived model.
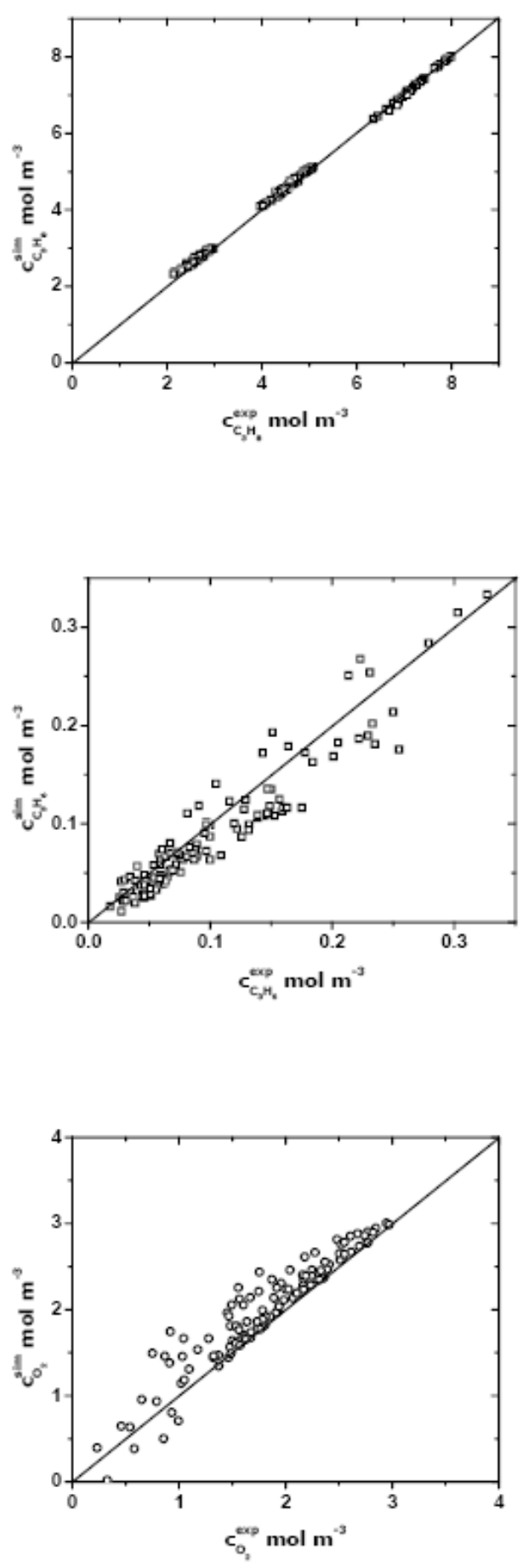

Fig. 7: Parity plots for simulated and experimental concentrations. (A) Propane, (B) Propene, (C) Oxygen.

Fig. 8 shows the differential heats of propane adsorption at V-SBA-15 as well as at the pure SBA-15 support. For both materials similar adsorption enthalpies in the range of $40 \mathrm{~kJ} \mathrm{~mol}^{-1}$ were determined. 


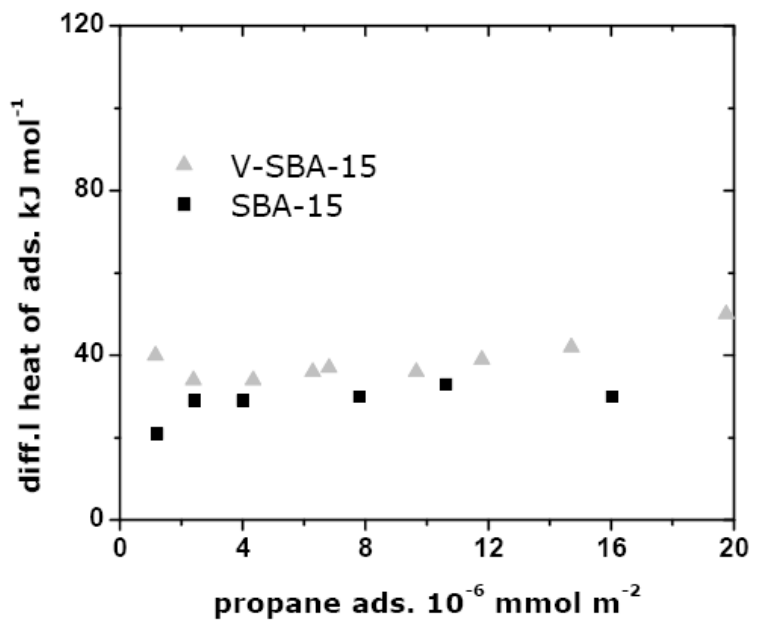

Fig.8: Differential heats of adsorption as a function of adsorbed propane for SBA-15 (pure support) and V-SBA-15.

For the determination of the adsorption equilibrium constant, a Langmuir isotherm was fitted to a set of experimental data with variation of propane pressure. The results are depicted in Fig. 9.

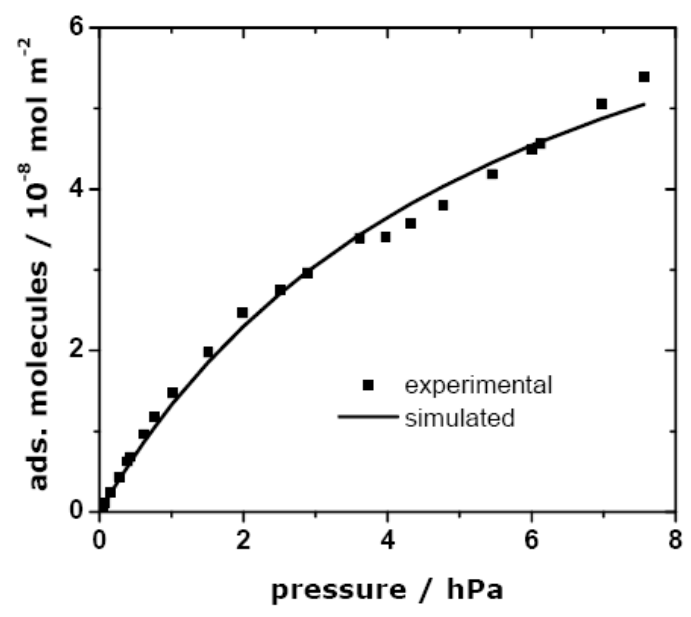

Fig. 9: Experimental data and simulation of the adsorption isotherm (Langmuir) of propane on V-SBA-15 at T=313 K.

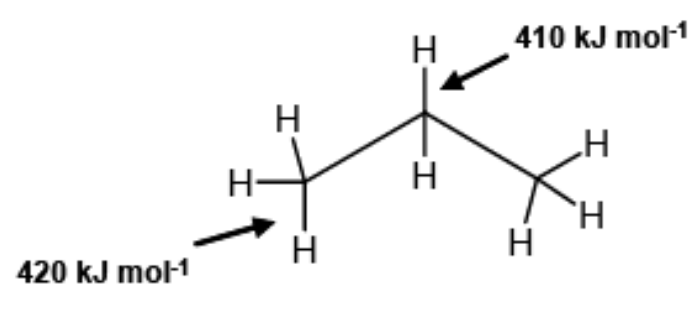

As can be seen, the simulation is in very good accordance with the experimental data. The parameters determined for the propane adsorption are given in Tab. 2 .

Table 2: Thermodynamic parameters determined for the propane adsorption on V-SBA-15.

\begin{tabular}{ll}
\hline $\mathrm{K}_{\infty}$ & $\Delta \mathrm{H}$ \\
$10^{-7}$ & $\mathrm{~kJ} \mathrm{~mol}^{-1}$ \\
\hline $2.1 \pm 0.2$ & $40 \pm 10$ \\
\hline
\end{tabular}

\section{Discussion}

Initial selectivities of almost $100 \%$ allow for the conclusion that ODP is described by a simple consecutive reaction in case of using SBA-15 supported vanadium catalysts. The simplification of the reaction network leads to the chosen kinetic model described in equation (10) and (11). A further important aspect concerning selectivity is the observation that it strongly increases with temperature. This was already found in a previous study for various other supported vanadia catalysts [24]. Only if the activation energy of the oxidative dehydrogenation is higher than the activation energy of propene combustion, the rate of propene production increases more with temperature than the rate of the consecutive propene combustion, leading to a higher selectivity of the desired product. Therefore a low activation energy is expected for the propene combustion, which is also in agreement with the lower bond strength of the allylic $\mathrm{C}-\mathrm{H}$ bond $\left(\sim 370 \mathrm{~kJ} \mathrm{~mol}^{-1}\right)$ in propene compared to the stronger secondary $\mathrm{C}-\mathrm{H}$ bond $\left(\sim 410 \mathrm{~kJ} \mathrm{~mol}^{-1}\right)$ in propane (Fig. 10). Please note that the difference in the weakest $\mathrm{C}-\mathrm{H}$ bond strength $\left(40 \mathrm{~kJ} \mathrm{~mol}^{-1}\right)$ corresponds approximately to the difference in activation energies of ODP and propene combustion $\left(70 \mathrm{~kJ} \mathrm{~mol}^{-1}\right)$ as calculated in this study.

Fig. 10: C-H bond strength in propane (left) and propene (right).

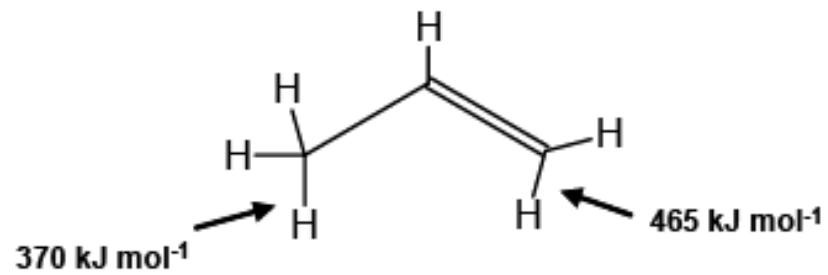


The reaction order of one for the propane dehydrogenation indicates the participation of propane in the rate determining step, which was already proven by isotopic tracer experiments done by Chen et al. [26] for different supported catalysts. The order of zero for oxygen proves a fast reoxidation of the catalyst, which can also be found for other catalysts investigated in the literature $[13,25]$. The reaction orders determined for the consecutive propene combustion of one for propene and zero for oxygen, respectively, suggest a participation of propene in the rate determining step of the consecutive combustion. This may be explained by the similarity of the active $\mathrm{C}-\mathrm{H}$ bond in both molecules. The good agreement of modelled and experimental data in Figure 6 indicates that the assumptions made for the simplification of the reaction network are appropriate.

In order to calculate the real activation energies from the determined apparent activation energies the elementary steps of ODP and the heat of adsorption of propane at the catalystshave to be known. Based on isotopic tracer experiments done by Chen et al. [26], the elementary steps for one propane conversion to propene are the following:

1. Adsorption of propane on lattice oxygen:

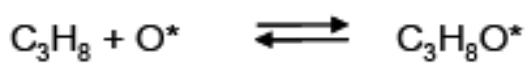

2. C-H bond abstraction from adsorbed propane involving a neighbouring oxygen atom:

$$
\mathrm{C}_{3} \mathrm{H}_{8} \mathrm{O}^{*}+\mathrm{O}^{*} \rightleftarrows \mathrm{C}_{3} \mathrm{H}_{7} \mathrm{O}^{*}+\mathrm{OH}^{*}
$$

3. Desorption of propene

$$
\mathrm{C}_{3} \mathrm{H}_{7} \mathrm{O}^{\star} \rightleftarrows \mathrm{C}_{3} \mathrm{H}_{6}+\mathrm{OH}^{\star}
$$

4. Formation of water under recombination of two neighbouring hydroxyl groups and formation of reduced vanadium centers depicted as *:

$$
\mathrm{OH}^{*}+\mathrm{OH}^{*} \rightleftarrows \mathrm{H}_{2} \mathrm{O}+\mathrm{O}^{*}+{ }^{*}
$$

5. Reoxidation of the catalyst with gas phase oxygen:

$$
\mathrm{O}_{2}{ }^{*}{ }^{*} \rightleftarrows \mathrm{H}_{2} \mathrm{O}+\mathrm{O}^{*}+{ }^{*}
$$

Their study revealed that the $\mathrm{C}-\mathrm{H}$ bond abstraction of the secondary carbon atom in propane is the irreversible, rate determining step in ODP and the overall rate of propane consumption can be derived from equations ( $\mathrm{r} 1)$ - (r5) as a typical Mars-van-Krevelen rate law (eq. 13):

$$
r_{C y H_{8}}=\frac{k_{2} \cdot K_{1} \cdot c_{C_{3} H_{8}}}{\left(1+\frac{\left(K_{4} \cdot c_{H_{2} O}\right)^{0.5} \cdot\left(k_{2} \cdot K_{1} \cdot c_{C, H_{8}}\right)^{0.25}}{\left(2 \cdot k_{5} \cdot c_{O_{2}}\right)^{0.25}}\right)^{2}}
$$

where $\mathrm{k}_{\mathrm{i}}$ is the respective rate constant and $\mathrm{Ki}$ the respective equilibrium constant for each reaction step (r1) - (r5). As found by Argyle et al. [27] by in-situ-UV-Vis spectroscopy, the reoxidation rate of the catalyst, described by $\mathrm{k}_{5}$ is about $10^{5}$ times higher than the rate determining $\mathrm{C}-\mathrm{H}$ bond abstraction, described by $\mathrm{k}_{2}$ and $\mathrm{K}_{1}$. Therefore eq. 13 simplifies to eq. 14:

$$
r_{C_{Y} H_{8}}=k_{2} \cdot K_{1} \cdot c_{C_{y} H_{8}}
$$

This rate law is equal to eq. 10 in case of a zero order reaction of oxygen as it was determined in the experiments. Therefore, the power law model, chosen for this study will result in the same kinetic describtion as a Mars-vanKrevelen type model does. Because of the high reoxidation rate constant $\mathrm{k}_{5}$, the kinetic parameters $\mathrm{K}_{4}$ and $\mathrm{k}_{5}$ cannot be determined accurately from a Mars-van-Krevelen model. A variation in these parameters has almost no impact on the rate of propane consumption. The product of $k_{2}$ and $K_{1}$ may also be written as:

$$
k_{2} \cdot K_{1}=k_{2,0} \cdot \exp \left(\frac{-\Delta E_{A, 2}}{R \cdot T}\right) \cdot K_{2,0} \cdot \exp \left(\frac{-\Delta H_{\text {at, } 2}}{R \cdot T}\right)
$$

Thus, the measured apparent activation energy is the sum of the real activation energy of ODP and the heat of adsorption of propane on the active site. In order to calculate the real activation energies of ODP, the heats of adsorption of propane on V-SBA-15 were determined. The measured adsorption enthalpies indicate a weak interaction between propane and vanadium surface species. The above discussion leads to the conclusion that the real activation energy for ODP is approximately $140 \mathrm{~kJ} \mathrm{~mol}^{-1}$.

Tab. 3 shows kinetic parameters determined by Grabowski et al. [28] for a high loaded silica supported vanadium catalyst. The apparent activation energy of the ODP is much lower $\left(70 \mathrm{~kJ} \mathrm{~mol}^{-1}\right)$ than the values derived in this study $\left(103 \mathrm{~kJ} \mathrm{~mol}^{-1}\right)$

Table 3: Literature data for ODP on silica supported vanadia

\begin{tabular}{lll}
\hline & $\mathrm{k}_{\mathrm{x}, 0}$ & $\mathrm{E}_{\mathrm{A}, \mathrm{app}, \mathrm{x}}$ \\
$\mathrm{x}$ & $\mathrm{s}^{-1}$ & $\mathrm{~kJ} \mathrm{~mol}^{-1}$ \\
\hline 1 & $512 \pm 56$ & $70 \pm 7$ \\
2 & $32000 \pm 3490$ & $48 \pm 5$ \\
\hline
\end{tabular}

This fact may be attributed to the high vanadium loadings in the mentioned study, which lead to formation of $\mathrm{V}_{2} \mathrm{O}_{5}$ for which the activation energy is actually measured in such case. Furthermore, mass transfer limitations, which especially occur at high vanadium loadings, were eventually not excluded. This makes the calculated kinetic parameters erroneous and leads to a lower activation energy for the ODP compared to the activation energy found in this study. The data, however also show, that the activation energy for 
the propene combustion is lower than for ODP, as it was expected. Reaction orders were not determined in the study discussed above, because it was based on an Elay-Rideal mechanism, which implies a rate dependence according to the adsorption behaviour of the substrate.

The experimentally determined apparent activation energies of the ODP are in good agreement with data derived from DFT calculations shown in Tab. 4 [17]. Theoretically determined values for the propene combustion could not be found.

Table 4: Comparison of experimentally and theoretically determined apparent activation energies. aActivation energy corrected by the heat of adsorption $\left(40 \mathrm{~kJ} \mathrm{~mol}^{-1}\right)$.

\begin{tabular}{|c|c|}
\hline study & $\begin{array}{l}\mathrm{E}_{\mathrm{A}, \mathrm{ODP}} \\
\mathrm{kJ} \mathrm{mol}^{-1}\end{array}$ \\
\hline this study & $103 \pm 6$ \\
\hline Bell et al. [16] & $112^{\mathrm{a}}$ \\
\hline Sauer et al. [17] & $123 \pm 5$ \\
\hline
\end{tabular}

\section{Conclusion}

The SBA-15 supported catalyst used for this study is an ideal model catalyst, because of its well investigated characteristics and the theoretically predictable reaction behavior. However, further preparative studies are necessary to understand the difference between vanadium monomers and associated species. The reaction orders of one for the oxidative dehydrogenation step of propane and the consecutive propene combustion indicate similar reaction

\section{References}

1. Chaar, M.A., D. Patel, H.H. Kung, J. Catal. 109 (1988) 463467.

2. Blasco, T., A. Galli, J.M.L. Nieto, F. Trifiro, J. Catal. 169 (1997) 203-211.

3. Cavani, F., N. Ballarini, A. Cericola, Catal. Today 127 (2007) 113-131.

4. Hess, C., J. Catal. 248 (2007) 120-123.

5. Inomata, M., K. Mori, A. Miyamoto, Y. Murakami, J. Phys. Chem. 87 (1983) $761-768$.

6. Khodakov, A., B. Olthof, A.T. Bell, E. Iglesia, J. Catal. 181 (1999) 205-216.

7. Andersson, S.L.T., Appl. Catal. A 112 (1994) 209-218.

8. Grabowski, R., J. Sloczynski, N.M. Grzesik, Appl. Catal. A 242 (2003) 297-309.

9. Routray, K., K.R.S.K. Reddy, G. Deo, Appl. Catal. A 265 (2004) 103-113.

10. Hess, C., G. Tzolova-Muller, R. Herbert, J. Phys. Chem. C 111 (2007) 9471-9479.

11. Hess, C., U. Wild, R. Schlog1, Microporous Mesoporous Mater. 95 (2006) 339-349.

12. Venkov, T.V., C. Hess, F.C. Jentoft, Langmuir 23 (2007) 1768-1777. mechanism for the activation of the two substrates. Higher activation energies of propane dehydrogenation as compared to the propene combustion indicate the participation of the weaker allylic $\mathrm{C}-\mathrm{H}$ bond of propene in the rate determining step of the propene combustion. In addition, this leads to higher propene selectivities at elevated reaction temperatures. A total oxidation of propane and propene with adsorbed molecular oxygen can be excluded, because in such case a higher reaction order for ODP and propene combustion would be expected. Zero reaction orders in case of oxygen indicate a fast catalyst reoxidation for ODP and propene combustion. The fast reoxidation also justifies a formal kinetic model approach as a reliable method for the determination of the apparent activation energies. For further investigations of the reoxidation reactions transient experiments need to be conducted. As shown by the calorimetric experiments, the active vanadium sites have no influence on the adsorption behaviour of propane. The values of the heat of adsorption are in the expected range of heterogeneous reactions.

\section{Acknowledgement}

This work was supported by the German Research Foundation (Deutsche Forschungsgemeinschaft, DFG) through the corporate research center "Structure, dynamics and reactivity of transition metal oxide aggregates" (Sonderforschungsbereich 546, http://www.chemie.huberlin. de/sfb546). Christian Hess thanks the DFG for providing an Emmy Noether fellowship.
13. Chen, K.D., A.T. Bell, E. Iglesia, J. Phys. Chem. B 104 (2000) 1292-1299.

14. Shee, D., T.V.M. Rao, G. Deo, Catal. Today 118 (2006) 288297.

15. Vannice, M.A., Catal. Today 123 (2007) 18-22.

16. Gilardoni, F., A.T. Bell, A. Chakraborty, P. Boulet, J. Phys. Chem. B 104 (2000) 12250-12255.

17. Rozanska, X., R. Fortrie, J. Sauer, J. Phys. Chem. C 111 (2007) 6041-6050.

18. Frank, B., A. Dinse, O. Ovsitser, E.V. Kondratenko, R. Schomäcker, Appl. Catal. A 323 (2007) 66-76.

19. Zhao, D.Y., Q.S. Huo, J.L. Feng, B.F. Chmelka, G.D. Stucky, J. Am. Chem. Soc. 120 (1998) 6024-6036.

20. Roman, P., A. Aranzabe, A. Luque, J.M. Gutierrezzorrilla, Mater. Res. Bull. 26 (1991) 731-740.

21. Coker, E.N., C.J. Jia, H.G. Karge, Langmuir 16 (2000) 1205 1210 .

22. Herbert, R., C. Hess, unpublished results.

23. Cassiers, K., T. Linssen, M. Mathieu, M. Benjelloun, K. Schrijnemakers, P. Van Der Voort, P. Cool, E.F. Vansant, Chem. Mat. 14 (2002) 2317-2324. 
24. Dinse, A., B. Frank, C. Hess, D. Habel, R. Schomäcker, J. Mol. Catal. A 289 (2008) 28-37.

25. Bottino, A., G. Capannelli, A. Comite, S. Storace, R. Di Felice, Chem. Eng. J. 94 (2003) 11-18.

26. Chen, K.D., A. Khodakov, J. Yang, A.T. Bell, E. Iglesia, J. Catal. 186 (1999) 325-333.
27. Argyle, M.D., K.D. Chen, E. Iglesia, A.T. Bell, J. Phys. Chem. B 109 (2005) 2414-2420.

28. Grabowski, R., J. Sloczynski, Chem. Eng. Process. 44 (2005) 1082-1093. 